\title{
AES Studies of Saturation in Surfactant Segregation Process in $\mathrm{Co} / \mathrm{Cu}$ Multilayers
}

\author{
M. Krupiński*, A. Dobrowolska, M. Kąc, A. Polit, Y. Zabila and M. MarszaŁek \\ The H. Niewodniczański Institute of Nuclear Physics Polish Academy of Sciences \\ Radzikowskiego 152, 31-342 Kraków, Poland
}

\begin{abstract}
The chemical composition of successive layers in a $\mathrm{Co} / \mathrm{Cu}$ multilayered system was studied during growth with Auger electron spectroscopy. Experiments were carried out on a sample with 10 repetitions of $\mathrm{Co}(1 \mathrm{~nm}) / \mathrm{Cu}(2 \mathrm{~nm})$ evaporated at a very low deposition rate in ultrahigh vacuum. A very small amount of $\mathrm{Bi}$ or $\mathrm{Pb}(0.06 \mathrm{~nm})$ was deposited on each $\mathrm{Cu}$ film in the system. The experimental data have shown that the concentration of Bi and $\mathrm{Pb}$ increases with the number of deposited trilayers up to coverage corresponding to 5 trilayers. At that point the concentration of the surfactant saturated. The changes in the surfactant concentrations are described with a simple model depicting the interaction of the surfactant atoms with the system and how the evolution of the segregation processes. It allows the prediction of the saturation concentration and helps to explain the behaviour of various elements used as a surfactant. The comparison between the theoretical predictions and the experimental results is also discussed.
\end{abstract}

PACS numbers: 82.80.Pv, 68.55.-a, 68.65.Ac

\section{Introduction}

Vapour deposited $\mathrm{Co} / \mathrm{Cu}$ multilayers with high quality interfaces exhibit significant giant magnetoresistance effect (GMR) [1]. These systems are extensively investigated as potential magnetic elements in ultrahigh-density data storage devices and for the future generation of magnetic random access memory. The value of magnetoresistance is mainly affected by the atomic scale structure, i.e. interfacial roughness [2]. Smooth $\mathrm{Co} / \mathrm{Cu}$ layer interfaces reveal larger GMR effect in comparison with rough and mixed interfaces. The larger roughness is experimentally found to occur predominantly at the Co-on- $\mathrm{Cu}$ interfaces. This results from the surface free energy which is smaller for $\mathrm{Cu}$ than for $\mathrm{Co}$ and leads to island growth of $\mathrm{Co}$ on $\mathrm{Cu}$. It causes that some reasonable similarity to layer-by-layer growth mode cannot be achieved, which is main difficulty in obtaining multilayers with optimal GMR value.

One of the solutions to this problem is the addition of surfactants, i.e. low surface energy metals like $\mathrm{Bi}$ or $\mathrm{Pb}$, to the films. The addition of a small amount of surfactant into the $\mathrm{Co} / \mathrm{Cu}$ multilayered system significantly reduces the degree of interfacial roughness [3]. The results showing the correlation between structural and magnetic properties of surfactant mediated $\mathrm{Co} / \mathrm{Cu}$ multilayers were published elsewhere $[4,5]$. Smoothing of the interfaces is a result of surfactant segregation to the surface of the $\mathrm{Co} / \mathrm{Cu}$ multilayers. It is of great interest to know how the segregation process proceeds and how the surfactant atoms interact with the other atoms in the multilayered system. This can be deduced from the

* corresponding author; e-mail: Michal.Krupinski@ifj.edu.pl chemical composition of successive layers, especially by examining the changes of surfactant contribution on the film surface during growth of the $\mathrm{Co} / \mathrm{Cu}$ system. This paper presents the results obtained by Auger electron spectroscopy (AES).

\section{Experimental details}

The sample preparation was done in ultrahigh vacuum at pressures below $10^{-7} \mathrm{~Pa}$. The substrates were $\mathrm{Si}(100)$ wafers with a native $\mathrm{SiO}_{2}$ layer, which were ultrasonically cleaned in organic solvents and rinsed in deionised water before the deposition process. The $[\mathrm{Co}(1 \mathrm{~nm}) / \mathrm{Cu}(2 \mathrm{~nm})]$ multilayers with 10 repetitions were deposited by sequential thermal evaporation. In addition, the surfactant was introduced in very small amounts $(0.06 \mathrm{~nm})$ at each interface of the $\mathrm{Co} / \mathrm{Cu}$ bilayer before Co deposition. The layers were deposited at room temperature, with rates around $0.6 \mathrm{~nm} / \mathrm{min}$ for $\mathrm{Co}$ and $\mathrm{Cu}$, and $0.06 \mathrm{~nm} / \mathrm{min}$ for $\mathrm{Bi}$ and $\mathrm{Pb}$. The working pressure was in the range of $10^{-6} \mathrm{~Pa}$. The film thickness was controlled during evaporation with a quartz thickness monitor.

The chemical composition of the surface was studied in situ after deposition of each film using AES. The spectrometer operating parameters were as follows: a beam energy of $3000 \mathrm{eV}$, beam current of $40 \mu \mathrm{A}$, and beam diameter of $300 \mu \mathrm{m}$. Except for $\mathrm{Co}, \mathrm{Cu}$ and surfactant presence, AES measurements also showed small amounts of oxygen and carbon. However, the concentration of these elements never exceeded 1\%. Furthermore, the composition of residual gases in the deposition chamber was analysed before and during deposition using quadrupole mass spectrometry (QMS). The measurements mainly showed the presence of nitrogen and hydrogen. Small concentrations of oxygen were observed too, however the partial pressure of oxygen always amounts to approximately 
$10^{-9} \mathrm{~Pa}$. For all $\mathrm{Co} / \mathrm{Cu}$ samples prepared in these experimental conditions the similar concentrations of oxygen and other chemical elements was observed.

\section{Results and discussion}

At each step of preparation the sample surface was examined in situ by AES. After the deposition of metals, the $M N N$ lines of $\mathrm{Co}(57 \mathrm{eV}), \mathrm{Cu}(66 \mathrm{eV})$ and the $N O O$ lines of $\mathrm{Bi}(105 \mathrm{eV}) / \mathrm{Pb}(97 \mathrm{eV})$ were observed. Well-defined $L M M$ lines of $\mathrm{Co}$ and $\mathrm{Cu}$, and $M N N$ lines of $\mathrm{Bi} / \mathrm{Pb}$ in the higher energy range (above $500 \mathrm{eV}$ ) were also registered, but they are not included in the analysis presented in this paper. The low energy Auger transitions were chosen because they are strongly surface sensitive. According to the equations of Cumpson and Seah [6], the $66 \mathrm{eV}$ copper Auger electrons have an effective attenuation length of $0.26 \mathrm{~nm}$, the $57 \mathrm{eV}$ cobalt electrons $0.25 \mathrm{~nm}$, and the $105 \mathrm{eV} / 97 \mathrm{eV}$ bismuth/lead electrons $0.25 \mathrm{~nm}$ and $0.24 \mathrm{~nm}$, respectively. Therefore, only electrons from the first few $\AA$ suffer no energy loss. After the initial deposition of $\mathrm{Co}$ and $\mathrm{Cu}$, differential Auger spectra showed only peaks originating from Co and $\mathrm{Cu}$. However, since the first deposition of surfactant layer, the $\mathrm{Bi} / \mathrm{Pb}$ peak was always visible in any subsequent measurements. This dependence indicates that the surfactant has continued to migrate to the surface during deposition. No appearance of Co on the $\mathrm{Cu}$ surface and $\mathrm{Cu}$ on the Co surface was observed, which is a confirmation of growth of continuous and closed films.

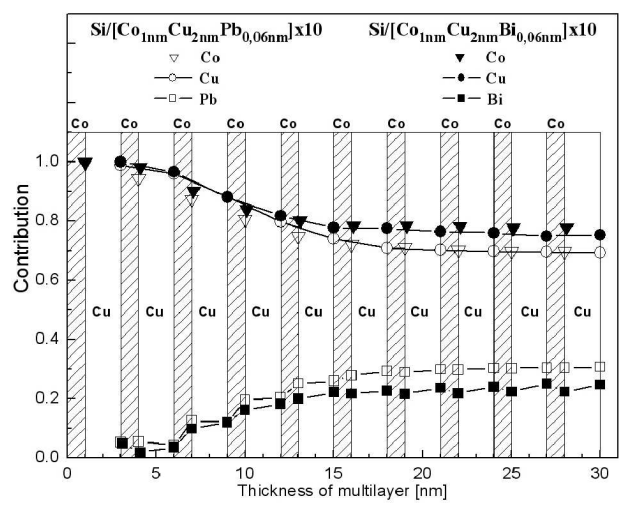

Fig. 1. Comparison of concentration profiles of $\left[\mathrm{Co}_{1 \mathrm{~nm}} / \mathrm{Cu}_{2 \mathrm{~nm}} / \mathrm{Bi}_{0.06 \mathrm{~nm}}\right] \times 10$ and $\left[\mathrm{Co}_{1 \mathrm{~nm}} / \mathrm{Cu}_{2 \mathrm{~nm}} /\right.$ $\left.\mathrm{Pb}_{0.06 \mathrm{~nm}}\right] \times 10$ samples calculated from Auger spectra taken after deposition of each metal. The shadowed boxes show the multilayer structure indicating the Co position. The lines are drawn to guide the eye. The points corresponding to the $\mathrm{Cu}$ and the surfactant metal concentration directly after surfactant deposition were removed for clarity of the picture.

Quantitative analyses of the AES measurements were done using elemental sensitivity factors and peak-to-peak heights in the differential Auger spectra [7]. Figure 1 shows atomic concentrations of $\mathrm{Cu}$, $\mathrm{Co}$ and $\mathrm{Bi} / \mathrm{Pb}$ in $\left[\mathrm{Co}_{1 \mathrm{~nm}} / \mathrm{Cu}_{2 \mathrm{~nm}} / \mathrm{Bi}_{0.06 \mathrm{~nm}}\right] \times 10$ and
$\left[\mathrm{Co}_{1 \mathrm{~nm}} / \mathrm{Cu}_{2 \mathrm{~nm}} / \mathrm{Pb}_{0.06 \mathrm{~nm}}\right] \times 10$ multilayers as a function of total thickness of the system. Concentration of Bi surfactant measured at each stage of deposition increased with the number of deposited $[\mathrm{Co} / \mathrm{Cu} / \mathrm{Bi}]$ trilayers up to a coverage of about $15 \mathrm{~nm}$, corresponding to 5 trilayers. After that the surfactant concentration saturated and was equal to approximately $23 \%$. It is also seen that the increase of surfactant concentration is accompanied by a simultaneous decrease of $\mathrm{Cu}$ and $\mathrm{Co}$ concentrations. The same behaviour was observed for the $\left[\mathrm{Co}_{1 \mathrm{~nm}} / \mathrm{Cu}_{2 \mathrm{~nm}} / \mathrm{Pb}_{0.06 \mathrm{~nm}}\right] \times 10$ multilayer system, except that the value of $\mathrm{Pb}$ saturation concentration was equal to approximately $30 \%$. The larger value of saturation concentration for $\mathrm{Pb}$ indicates a stronger segregation effect than for $\mathrm{Bi}$.

\section{Model of saturation in surfactant segregation process}

Saturation effect, appearing during the surfactant segregation, can be described by the simple model presented below. Let us consider first the deposition process of the $\left[\mathrm{Co}_{1 \mathrm{~nm}} / \mathrm{Cu}_{2 \mathrm{~nm}} / \mathrm{Bi}_{0.06 \mathrm{~nm}}\right] \times 10$ and $\left[\mathrm{Co}_{1 \mathrm{~nm}} / \mathrm{Cu}_{2 \mathrm{~nm}} / \mathrm{Pb}_{0.06 \mathrm{~nm}}\right] \times 10$ systems. After the first $\mathrm{Co} / \mathrm{Cu}$ bilayer, a $0.06 \mathrm{~nm}$ thick surfactant film is deposited, which causes that the $\mathrm{Bi} / \mathrm{Pb}$ concentration $c_{0}$ is observed on the surface of the sample. Then, the surfactant layer is covered by the next $\mathrm{Co} / \mathrm{Cu}$ bilayer. Because of the segregation process, some number of surfactant atoms flow to the top of the sample and the resulting surfactant concentration on the second $\mathrm{Co} / \mathrm{Cu}$ bilayer is equal to

$$
c_{1}=x_{1} c_{0},
$$

where $c_{0}$ and $c_{1}$ are surfactant concentrations on the first and the second $\mathrm{Co} / \mathrm{Cu}$ bilayer surface respectively, and $x_{1}$ stands for the fraction of atoms which diffused from the first to the second bilayer interface. In this paper the subscript $n(n=0,1,2,3, \ldots)$ is used in reference to the number of successive $\mathrm{Co} / \mathrm{Cu}$ bilayer interfaces. In the subsequent step of the deposition process, $0.06 \mathrm{~nm}$ thick surfactant film is again added to the system and the next $\mathrm{Co} / \mathrm{Cu}$ bilayer is deposited. The segregation process still occurs, leading to a new surfactant concentration on the surface of the sample

$$
c_{2}=x_{2}\left(c_{1}+c_{0}\right) \text {. }
$$

Substituting Eq. (2) with Eq. (1) we get

$$
c_{2}=c_{0}\left(x_{2}+x_{2} x_{1}\right) \text {. }
$$

Considering the deposition process step by step, we can derive a general formula for surfactant concentration on the sample surface consisting of any number $N$ of $\mathrm{Co} / \mathrm{Cu}$ bilayers

$$
\begin{aligned}
c_{\mathrm{N}} & =c_{0} \sum_{k=1}^{\mathrm{N}} \prod_{n=k}^{\mathrm{N}} x_{n} \\
& =c_{0}\left(x_{\mathrm{N}}+x_{\mathrm{N}} x_{\mathrm{N}-1}+\ldots+x_{\mathrm{N}} x_{\mathrm{N}-1} \ldots x_{1}\right) .
\end{aligned}
$$


If each $x_{n}<1$, the above-mentioned sum is convergent, which signifies that the surfactant contribution saturates as the number of layers increases. If we assume that the segregation process is activated thermally, the probability of the surfactant atoms moving from the surfactant layer to the $\mathrm{Co} / \mathrm{Cu}$ layer is given by the Boltzmann distribution. Therefore, the following formula for $x_{n}$ can be derived:

$$
x_{n}=-C\left(\frac{E_{0} c_{n-1}}{k_{\mathrm{B}} T}+1\right)=A c_{n-1}-C .
$$

$E_{0}$ is an effective activation energy. It represents the average energy (calculated for one atom) which is needed to move the surfactant atom from the surfactant layer to the $\mathrm{Co} / \mathrm{Cu}$ bilayer. $C$ is a system constant that depends on the thickness of the $\mathrm{Co} / \mathrm{Cu}$ bilayer and the diffusion coefficient of $\mathrm{Bi}$ or $\mathrm{Pb}$ in $\mathrm{Co} / \mathrm{Cu}$. It is seen that apart from activation energy $E_{0}$, temperature $T$ is one of the most important parameters determining the segregation process. The model predicts the increase of $x_{n}$ with temperature which results in the rise of saturation concentration. However, there should be mentioned that the deposited material also carries thermal energy onto the surface. Therefore, the effective temperature is not exactly the bulk temperature, which should be taken into account in more advanced models.

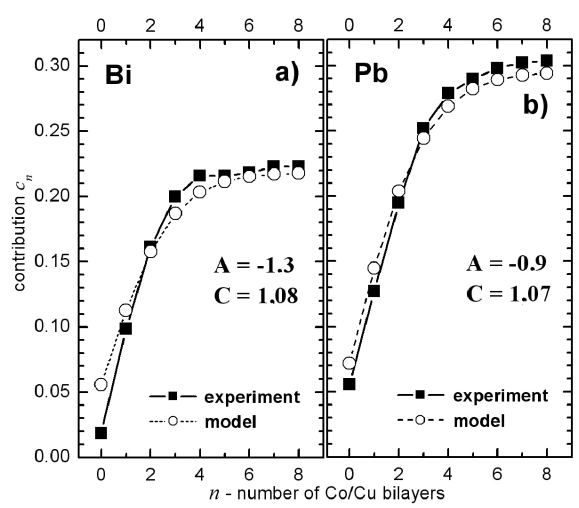

Fig. 2. Change of the surfactant concentrations on the surface of $\mathrm{Co} / \mathrm{Cu}$ bilayers for (a) $\left[\mathrm{Co}_{1 \mathrm{~nm}} / \mathrm{Cu}_{2 \mathrm{~nm}}\right.$ $\left.\mathrm{Bi}_{0.06 \mathrm{~nm}}\right] \times 10$ and (b) $\left[\mathrm{Co}_{1 \mathrm{~nm}} / \mathrm{Cu}_{2 \mathrm{~nm}} / \mathrm{Pb}_{0.06 \mathrm{~nm}}\right] \times 10$ systems as a function of $\mathrm{Co} / \mathrm{Cu}$ bilayer number. Squares correspond to results of the experiment and circles represent simulation obtained using formulae (4) and (5). $A$ and $C$ were fitted parameters in these simulations. The lines are drawn to guide the eye.

Using the aforementioned formulae, it is possible to describe the change of surfactant contribution on the successive interfaces in the system. Figure 2 shows the change of the surfactant concentration as a function of $\mathrm{Co} / \mathrm{Cu}$ bilayer number. The squares correspond to experimental results and the circles represent theoretical calculations using formulae (4) and (5). $A$ and $C$ were fitted parameters in these simulations. Good correspondence between simulated and experimental data is ob- served. The absolute value of the ratio $A / C$ is a measure of the effective activation energy necessary to change the place of surfactant atom in the system. Particularly, it should depend on energy, which is needed to break the bond between surfactant atoms and to move the atom to the $\mathrm{Co} / \mathrm{Cu}$ bilayer. Therefore, the ratio $A / C$ should be any unknown monotone function of bond enthalpy of the surfactants. According to the fit parameters, the ratio $A / C$ for $\mathrm{Bi}$ is greater than for $\mathrm{Pb}$. The same relationship exists for published bond enthalpies of the surfactants, which amount to $200.4 \mathrm{~kJ} / \mathrm{mol}$ for $\mathrm{Bi}$ and $86.6 \mathrm{~kJ} / \mathrm{mol}$ for $\mathrm{Pb}[8]$. It suggests that the bond energy between the surfactant atoms is one of the factors determining the saturation contribution in the segregation process.

\section{Conclusions}

The $\mathrm{Bi}$ and $\mathrm{Pb}$ behaviour and the changes of the chemical composition of interfaces in surfactant mediated $\mathrm{Co} / \mathrm{Cu}$ system were analyzed with Auger electron spectroscopy. AES spectra showed the presence of surfactants on all surfaces of subsequently deposited metal films, which indicates that they tend to segregate to the surface during deposition. Moreover, a simple model describing the level of surfactant concentration on the successive interfaces was proposed. It predicts quick saturation of the surfactant concentration after a few $\mathrm{Co} / \mathrm{Cu}$ bilayers and additionally suggests an increase of the saturation concentration of the surfactant with an increase in temperature. Finally, it was supposed that the small bond enthalpy for $\mathrm{Pb}$ causes the higher observed saturation concentration in the segregation process in comparison with $\mathrm{Bi}$. We have shown using the simple dimensionless model that we are able to reproduce the experimentally observed movement of surfactant front to the surface, however, to get more precise and quantitative information the more complex model has to be used.

\section{References}

[1] S.S.P. Parkin, Z.G. Li, D.J. Smith, Appl. Phys. Lett. 58, 2710 (1991).

[2] M. Suzuki, Y. Taga, Phys. Rev. B 52, 361 (1995).

[3] M. Marszałek, A. Polit, V. Tokman, Y. Zabila, I. Protsenko, Surf. Sci. 601, 4454 (2007).

[4] H. Wider, V. Gimple, W. Evenson, G. Schatz, J. Jaworski, M. Marszałek, J. Appl. Phys. 95, 5837 (2004).

[5] M. Marszałek, O. Bolling, J. Jaworski, M. Kąc, R. Kruk, V. Tokman, B. Sulkio-Cleff, Phys. Status Solidi 1, 3239 (2004).

[6] P.J. Cumpson, M.P. Seah, Surf. Interface Anal. 25, 430 (1997).

[7] P.M.A. Sherwood, in: Practical Analysis by Auger and X-ray Photoelectron Spectroscopy, Eds. D. Briggs, M.P. Seah, 2nd ed., Wiley, Chichester (U.K.) 1990.

[8] J.A. Kerr, in: A Ready-Reference Book of Chemical and Physical Data (CRC Handbook of Chemistry and Physics, Ed. D.R. Lide, 81st ed., CRC Press, Boca Raton (USA) 2000. 